\title{
Inadvertent VFR-into-IMC Flights: A Qualitative Approach to Describing GA Pilots' First-Hand Experiences
}

\author{
Michael A. Gallo, Hussain Alhallaf, Selcuk Baran, Ismael Cremer, Christopher \\ Finn, Indira Maharaj, A. Selim Ozyurek, A. Erdal Peker, Brian Reese, Isa \\ Tuncman, R. Tolga Turgut, and Kole O. Uhuegho \\ Florida Institute of Technology
}

\begin{abstract}
The phenomenon of encountering instrument meteorological conditions (IMC) on a visual flight rules (VFR) flight has been the focus of several previous studies. Most of these past studies, though, have involved examining various databases quantitatively or via a mixedmethods approach in search of possible causal factors such as pilot characteristics, weather conditions, aircraft type, and time of day. Missing from the literature are qualitative studies that tell the story of pilots who actually experienced such flights. To help fill this gap in the aviation literature, the purpose of the current study was to describe the first-hand experiences of GA pilots who inadvertently flew VFR-into-IMC. Participants consisted of 11 male pilots who previously had flown from VFR-into-IMC inadvertently at some point during their aviation career. The study used a phenomenological approach to describe participants' shared experiences and then applied grounded theory to develop a set of conjectures derived inductively from participants' responses. Using Spradley's (1979) domain analysis to categorize common themes and patterns, the major domains of Weather Considerations and Expectations, Thoughts and Actions, and Postflight Experiences emerged. Major findings from the first domain revealed that as part of their preflight actions prior to departure, participants received a weather briefing, gave little consideration to overall weather conditions, neither expected nor anticipated IMC, and used a variety of communication resources to keep current with weather related issues. Major findings from the second domain revealed that participants recognized changes in the weather en route, used various communication resources to assess their current condition, reacted to IMC by trying to avoid and escape it, expressed feelings of trepidation about what they should do, were surprised over how the weather was not what they expected, and reverted to their training to get out of IMC. Major findings from the third domain revealed that participants' postflight actions ranged from doing nothing to submitting a report to NASA's ASRS, and that lessons learned included acquiring a heightened sense of situational awareness, a need to do a better job in alternative planning, and a greater appreciation for the weather. A comparison of these findings to past studies and theory are discussed, and implications and recommendations for practice and research are provided.
\end{abstract}

\section{Introduction}

Flying under visual flight rules (VFR) and continuing into instrument meteorological conditions (IMC) "is one of the most consistently lethal mistakes in all of aviation. Since 2002, more than $86 \%$ of all fixed-wing VFR-into-IMC accidents have been fatal, a higher proportion than for mid-air collisions, wire strikes, or pilot incapacitation" (Aircraft 
Owners and Pilots Association, 2015, p. 1). According to a U.S. National Transportation Safety Board (NTSB) report, "about two-thirds of all general aviation (GA) accidents that occur in instrument meteorological conditions (IMC) are fatal, a rate much higher than the overall fatality rate for GA accidents" (NTSB, 2005, p. vii), and that VFR-into-IMC accidents were the number one cause of GA fatalities between 1983 and 2002 (Bazargan, 2005).

The VFR-into-IMC phenomenon is not restricted to the United States. For example, Canadian data for 1976-1985 were consistent with U.S. data for the same 10-year period. In the U.S., VFR-into-IMC accidents comprised $4 \%$ of GA accidents but accounted for $19 \%$ of the total fatalities (NTSB, 1989). In Canada, VFR-into-IMC accidents comprised $6 \%$ of GA accidents but accounted for $26 \%$ of all fatalities (Aviation Safety Study, 1990). Although the annual number of VFR-into-IMC accidents in Canada has decreased, "the annual number of fatalities in VFR-into-IMC accidents has remained generally constant" (Aviation Safety Study, 1990, p. 2). Similarly, in a review of 491 aviation accident and incident reports drawn from the Australian Transport Safety Bureau (ATSB) occurrence database, Batt and O'Hare (2005) reported that 75.6\% of VFR-into-IMC accidents involved a fatality. Batt and O'Hare also concluded that the results of their study confirmed previous findings from NTSB (1989), Aviation Safety Study (1990), Goh and Wiegmann (2001), and Aircraft Owners and Pilots Association (AOPA, 2002).

Given that the average time from cloud entry to loss of control or ground impact is 178 seconds for pilots who lack adequate instrument flight training (Wilson \& Sloan, 2003), flying from VFR-into-IMC without proper ratings or currency puts safety at risk. To gain insight into the VFR-into-IMC phenomenon, considerable attention has been given across the research spectrum ranging from studies in which archival data were analyzed to laboratory based intervention studies and theoretical explanations. With few exceptions, though, most of these studies have been empirical in nature. No studies to date have examined this phenomenon using a qualitative research approach. As a result, we endeavored to augment the current literature by conducting a qualitative study to describe the first-hand experiences of pilots who experienced a VFR-into-IMC flight.

\section{Review of the Literature}

\section{Examining Data from NTSB, FAA, ASRS, and ADAB Records}

In a study to determine causal factors that contributed to GA pilots' decision-making process to fly from VFR into IMC, Goh and Wiegmann (2001) analyzed fixed wing GA aircraft accident reports from NTSB and Federal Aviation Administration (FAA) databases from January 1990 to December 1997. Goh and Wiegmann found that during this targeted 8 -year period the NTSB classified 409 accidents as being the result of VFR-into-IMC (approximately 50 per year). Of these 409 accidents, 92 (22.5\%) were classified as being inadvertent, and 283 of these 409 cases $(69.2 \%)$ were related to weather conditions. As noted by Goh and Wiegmann (p. 5), because the NTSB category of "inadvertent" means pilots did not intentionally fly VFR-into-IMC, these findings suggest that pilots who were involved in VFR-into-IMC accidents "may not have realized that the weather had 
deteriorated," and they support the explanation that "erroneous assessment of weather conditions may cause at least some pilots to fly into IMC unwittingly."

Ison (2014) examined 80 fatal GA accident reports from the NTSB (2013) accident database to determine what pilot- and situation-specific characteristics were correlated to VFR-into-IMC GA accidents: 40 involved VFR-into-IMC accidents and 40 involved nonVFR-into-IMC accidents. Pilot characteristics included certification, age, flight time, and whether or not the pilot received a weather briefing. Situation-specific characteristics included time of accident, type of terrain at the crash site, whether or not a flight plan was filed, and if there was contact with air traffic control (ATC) at the time of the crash. Ison also compared these characteristics to accident type: VFR-into-IMC vs. non-VFR-intoIMC. Of the eight targeted factors, only two were significant: type of terrain at the crash site (mountainous/elevated) and weather briefing (received), with the latter being the stronger of the two. Ison reported that "those involved in a fatal continued VFR flight into IMC were 19 times more likely to have received a weather briefing, controlling for other factors" (p. 16), and that "VFR into IMC accidents were 10 times more likely to involve mountainous/elevated terrain" (p. 16). When examined relative to accident type, Ison reported when controlling for terrain "If an accident was classified as VFR into IMC, it was more likely that the pilot received a weather briefing" (p. 17). Relevant to the current study, Ison concluded:

Considering that pilots who were involved in continued VFR into IMC received a weather briefing, it points to the need to focus on weather education as well as hazardous pilot attitudes. Perhaps pilots are not heeding the warnings of weather briefers or sources either because they do not grasp the required knowledge to evaluate weather reports and factors (or) they may feel as though they are invulnerable due to having made the flight before, overconfidence, or other negative attitudes. (p. 22)

Knecht and Lenz (2010) examined interview data from 100 pilots who submitted weather-related incident reports in 2005-2006 to the Aviation Safety Reporting System (ASRS), which is a FAA sponsored program administered by the National Aeronautics and Space Administration (NASA). ASRS is a repository of aviation safety incident reports submitted voluntarily by "pilots, controllers, flight attendants, maintenance personnel, dispatchers, and other users of the National Airspace System, or any other person...(who knows of)...actual or potential discrepancies and deficiencies involving the safety of aviation operations" (ASRS, 2015, p. 1). The pilots who participated in Knecht and Lenz's study agreed to complete a questionnaire as a follow-up to the incident report they submitted. The questionnaire was mailed to the pilots after they gave their permission and consisted of sets of questions partitioned into six sections: (a) pilots' flight planning and weather briefings, (b) incident information, (c) contributing factors and consequences, (d) aircraft equipment, (e) instrument-related information, and (f) summary information. Knecht and Lenz analyzed the data from the first four sections of the questionnaire from a whole group perspective, and then disaggregated the data into three groups: non-instrument rated (non-IR) pilots, air transport pilots (ATP), and non-ATP IR pilots. 
With respect to the overall group, Knecht and Lenz (2010) found that 95 of the 100 pilots received preflight weather briefings and used various sources, including Flight Service Station (FSS), Direct User Access Terminal System (DUATS), National Oceanic \& Atmospheric Administration/National Weather Service NOAA/NWS, commercial vendors, The Weather Channel (TWS), and En-route Flight Advisory Service (Flight Watch), with 32 pilots using a single source. When compared to the weather forecast, 19 pilots reported that the actual weather was worse on departure, 35 reported it was worse en-route, and 38 reported it was worse at the destination. Some of the recovery strategies pilots reported using included descending and staying below the weather, deviating around the weather, climbing above the weather, and landing at an alternative site.

With respect to the 27 non-IR pilots, 5 were suspected of not obtaining an adequate preflight weather briefing, 13 had no actual instrument hours at the time of their incident, and 7 had between 8 and 128 instrument hours. During the en route phase of their respective flights, 14 reported they attempted to receive ATC assistance. As for their recovery strategies, the three most frequently used were to descend to stay below the weather, perform a 180-degree turn, and land at an alternative site. Knecht and Lenz (2010) concluded their findings by remarking that the non-IR pilot group appeared to have the least training and experience.

With respect to the 55 non-ATP IR pilots, all acquired a preflight weather briefing, with 32 of them using FSS as their primary source, and 36 reported that the actual weather was worse than what was predicted during one or more of the three flight phases. As for their recovery strategies, 20 of the pilots in this group descended to stay below the weather, but 30 flew directly into clouds or fog prompting Knecht and Lenz (2010) to surmise that nonATP IR pilots are "More likely to fly straight into adverse weather, rather than deviate around it" (p. 16). Nearly two thirds (62\%) indicated they tried to receive ATC assistance en route. Comparing non-IR and non-ATP IR pilots on weather-related differences, Knecht and Lenz reported that non-IR pilots are more deficient with respect to (among others) training, experience (number of flight hours), aircraft performance, and likelihood of recovery by deviating around the weather. (Reviews of the ATP group are not presented here because they are not relevant to the current study.)

Knecht and Lenz (2010, p. 21) concluded that their analysis revealed two major at-risk groups when applied to the context of VFR-into-IMC: non-IR pilots and "newly minted" IR pilots, and that each group has its own distinct training needs. Knecht and Lenz wrote: "Both groups need to be proactive about developing alternatives in the event of adverse weather. This means thinking about alternative actions before they are needed, not waiting until the last minute" (p. 22). Knecht and Lenz also indicated:

Finally, both IR and non-IR pilots need a way to develop and maintain weather expertise in a safe setting. The most obvious and cost-effective ways to do this are through PC- and Web-based weather-skill testing and training programs, both in traditional knowledge-based format and flight simulator format. (p. 22) 
As an alternative to examining accident records from NTSB/FAA and ASRS databases, Shappell et al. (2010) focused on two resources that had not been used in the past. The first was the FAA's Administrator's Daily Alert Bulletins (ADABs), which contain daily reports of aerospace accidents, incidents, and pilot deviations. The second was air traffic control (ATC) flight assist records of pilot-ATC communications related to safety issues such as ATCs helping pilots navigate around adverse weather. Pertinent to the current study, one area Shappell et al. focused their attention on was VFR-into-IMC events. Interview data from 25 pilots who experienced an adverse weather event were used for their study. Interview questions were developed from surveys used by NASA (2007) and Knecht (2008a, 2008b) and were mostly closed-ended. The questions were partitioned into several sections: aircraft information, pilot demographics (personological characteristics, pilot experience, and training), event information (participants described their weather encounter in detail), preflight planning information, and en route decision-making.

Some of the major findings relevant to the current study included (pp. 6-9): (a) all pilots acquired weather information as part of their preflight planning on the day of the weather encounter; (b) the pilots used a variety of sources to access weather information, and the three most frequently cited sources they consulted on the day of the weather encounter were FSS, NOAA, and the Weather Channel; (c) most of the flights were forecast to depart VMC; (d) most of the pilots encountered adverse weather en route; and (e) most pilots reported being aware of the adverse weather while en route. Based on their findings, Shappell et al. indicated that it appears GA pilots are not disregarding the rules but instead are simply committing decision errors, and that "Contrary to what the accident record seems to suggest, flight into adverse weather seems to be primarily due to the lack of appreciation/understanding of the hazards associated with adverse weather" (p. 12).

\section{Laboratory Based Intervention Studies and Theory Testing}

As noted earlier, several theories also have been applied to help explain VFR-into-IMC flights. These theoretical explanations include: (a) prospect theory (Levy, 1992), which posits that pilots who frame diverting from the planned flight as a loss will tend to continue the flight whereas pilots who frame diversion as a gain will tend to divert; (b) situation assessment (Wiegmann, Goh, \& O'Hare, 2002), which posits that pilots fly into adverse weather because they do not fully realize the situation and they cannot understand the changes in and severity of the weather; and (c) the application of the theory of sunk costs (Arkes \& Blummer, 1985), which posits that if pilots encounter adverse weather late, then they are more likely to continue due to the investment made.

O'Hare and Smitheram (1995) applied prospect theory in a study that involved 24 volunteer male pilots from New Zealand. Participants were presented two decision scenarios via a computer-generated cross-country flight within New Zealand. In both scenarios participants were: (a) informed en route that the weather was deteriorating at the destination site, (b) given 5 minutes to acquire all the information they needed to make a decision, and (c) presented with two options: continue with the flight or return to the departure site. They then assessed the confidence they had in their decision on a 7-point scale $(1=$ confident, $7=$ not confident $)$. This was followed by a postdecisional 
questionnaire in which participants determined the extent to which eight different factors contributed to their decision to continue or divert. These factors, which were assessed on a 7-point scale ranging from very important to not important, included tangible gains and losses for self, tangible gains and losses for others, self-approval/disapproval, and social approval/disapproval.

With respect to the first decision scenario, O'Hare and Smitheram (1995) reported there was no significant relationship between participants' gain or loss preference and their decision to continue the flight. Participants who reported they normally consider the decision to continue a flight in terms of gains were not any more likely to divert, and pilots who reported they normally consider the decision in terms of losses were not any more likely to continue. O'Hare and Smitheram also reported that the background variables they targeted (age, flight hours in various categories, highest certificate, date of most recent rating, and instrument rating) were not significant predictors to whether a participant had a preference for a loss or gain frame. With respect to the second decision scenario, O'Hare and Smitheram reported a significant relationship between the framing manipulation and participants' decision to continue or divert. "Participants in the loss frame were significantly more likely to elect to continue with the flight than participants in the gain frame" (p. 363). There also was no significant difference in the time it took participants to determine whether to continue or divert between the two scenarios, but there was a significant difference in participants' confidence level with respect to their decision. "The pilots' mean confidence rating for the first scenario was significantly lower than their mean rating for the second scenario" (p. 364). Although findings from the first scenario did not support prospect theory, the effect of the framing manipulation in the second scenario provided evidence in support of prospect theory. As useful as O'Hare and Smitheram's study is to understanding the VFR-into-IMC phenomenon, however, a limitation to their findings is that they were based on a simulation and not real-world experiences.

Wiegmann et al. (2002) tested their situation assessment hypothesis by examining pilots' decisions to continue or divert from a VFR-into-IMC flight during a dynamic simulation of a cross-country flight. They predicted that more experienced pilots would divert sooner than less experienced pilots. Thirty-six pilots between the ages of 18 and 62 years old participated in the study. Their total flight time ranged from 63 to 1,983 hours, and their total cross-country flight time ranged from 4 to 550 hours. Twenty-five of the pilots were instrument rated. The participants were divided into two groups: a short group, which experienced degrading weather early after departure, and a long group, which experienced degrading weather later en route.

The results revealed that all pilots continued flight past the point at which the weather began to degrade. Thirty-five pilots ultimately diverted and one pilot crashed while continuing into adverse weather. Results of Mann-Whitney $U$ tests revealed that pilots in the short condition traveled significantly farther and longer into adverse weather. About one third of the pilots accurately estimated visibility and cloud ceiling, and a relatively equal proportion of pilots either overestimated or underestimated weather conditions. Equal portions of pilots from the short and long flight conditions estimated visibility accurately. Wiegmann et al. (2002) indicated that the location at which adverse weather 
conditions were encountered during a flight affected a pilot's decision to continue with the flight, with the short group of pilots traveling longer into deteriorating weather. As was the case with O'Hare and Smitheram (1995), although Wiegmann et al.'s study brought a new perspective to understanding VFR flight into IMC, their findings are limited because the study was conducted in a simulator and did not involve pilots experiencing an actual VFRinto-IMC flight.

\section{Concluding Statement of Previous Studies}

The literature is replete with studies and theories relative to VFR-into-IMC flights. Past studies have examined various databases of archived accident records to determine if there are any common factors relative to: pilot characteristics such as age, flight time, certifications, and licenses; preflight weather briefings such as what weather providers (e.g., FSS) and weather products (e.g., METAR, TAF, ASOS, and AWOS) pilots used; and situation-specific characteristics such as terrain and weather. Past studies also have tested various explanation theories, including prospect theory, situation assessment, and the theory of sunk costs. Although these studies have been beneficial to understanding this phenomenon, findings either have been based on observational studies such as a content analysis of accident reports or involved interventions using simulator or simulation-based exercises. With the exception of Knecht and Lenz (2010) and Shappell et al. (2010), there is a dearth of studies that provide first-person accounts of pilots who personally experienced an inadvertent VFR-into-IMC flight. One limitation of these interview-based studies, though, is that the pilots were identified from archived ASRS or ADAB records. Furthermore, the data acquired from these pilot interviews were mostly quantitative and analyzed from a descriptive statistics perspective with findings being reported via frequencies and percentages. To address the design, sampling, and data analysis limitations of past studies, the literature needs to include studies that (a) are not based on simulations, (b) do not rely on archived records for data mining purposes or to identify and interview pilots who survived a VFR-into-IMC flight, and (c) do not rely on quantitative data analysis procedures. The literature surrounding the VFR-into-IMC phenomenon would benefit from studies that use a qualitative research methodology, which was the approach used for the current study.

\section{Purpose Statement and Research Questions}

The purpose of the study was to describe the first-hand experiences of pilots who inadvertently flew VFR-into-IMC. In the context of the current study, pilots were defined as GA pilots involved in "civil aviation operations other than scheduled air services and non-scheduled air transport operations for remuneration or hire" (FAA, 2014, p. G-1). This definition was further restricted to GA pilots who engaged in noncommercial and nonmilitary, fixed-wing flight operations other than gliders. However, no restrictions were placed on the number of licenses and ratings, IFR experience, or age. Three research questions guided the study: (a) In what way do pilots use weather-related information throughout their VFR-into-IMC flight? (b) What are pilots' thoughts and actions when they realize they are in IMC? and (c) What are pilots' retrospective thoughts on their VFR-intoIMC flight experience? 
Table 1

Summary of Sample Demographics

\begin{tabular}{lrrrrrcccccc}
\hline & \multicolumn{4}{c}{ Flight Hours } & \multicolumn{3}{c}{ Age } & \multicolumn{4}{c}{ Type/Number of Licenses $^{\mathbf{a}}$} \\
\cline { 2 - 11 } Sample & $\boldsymbol{N}$ & $\boldsymbol{M}$ & Range & $\boldsymbol{M}$ & Range & PPL & CPL & ATP & IR & ME \\
2014 & 6 & 4,627 & $200-9000$ & 42.5 & $22-64$ & 6 & 4 & 2 & 4 & 3 \\
2015 & 5 & 411 & $250-1000$ & 31.4 & $25-45$ & 5 & 4 & 0 & 5 & 5 \\
Overall & 11 & 2,519 & $200-9000$ & 36.9 & $22-64$ & 11 & 8 & 2 & 9 & 8 \\
\hline
\end{tabular}

Note. All participants were male GA pilots.

${ }^{\text {aPPL }}=$ Private Pilot License, $\mathrm{CPL}=$ Commercial Pilot License, ATP $=$ Airline Transport Pilot, IR = Instrument Rated, and ME = Multiengine Rated.

\section{Methodology}

\section{Context}

The current study was conducted over a 2-year period (2014 and 2015) as a class project for an introductory graduate course in qualitative research design. The course was taught by the major author and consisted of three male students in Spring 2014, and eight students (one female) in Spring 2015, all of whom were part of the research team and are listed as coauthors. The students had diverse backgrounds across a broad spectrum of the aviation industry, including flight instruction, airframe and power plant maintenance, aviation human factors, aviation management and consultant, and aviation analyst. Four students were employed by an international commercial airline, one student was a fulltime flight instructor, four students were fulltime university faculty members or administrators, and two were fulltime students.

Two purposive samples were selected. The 2014 sample consisted of six male pilots denoted as participants P1-P6, and the 2015 sample consisted of five male pilots denoted as participants P7-P11. Participants from both samples previously had flown from VFRinto-IMC inadvertently at some point during their aviation career. As noted in Table 1, which contains an aggregate summary of the participants' demographics, the 2014 participants were older and had more experience with respect to flight time, and 9 of the 11 participants were instrument rated.

\section{Research Design and Data Collection Methods}

The current study employed a qualitative research methodology, specifically, phenomenology. This approach was appropriate because the primary purpose was "to describe the essence of a lived phenomenon" (Creswell, 2013, pp. 104-105). In the context of the current study, this "lived phenomenon" was an inadvertent VFR-into-IMC flight, and the unit of analysis was several individuals who shared this experience. In addition to describing pilots' shared experiences, the participants' views also were used to develop a set of conjectures derived inductively from their responses. This grounded theory approach 
(Glasser \& Strauss, 1967; Strauss \& Corbin, 1990) was used to further enhance the answers to the research questions.

Although interviews are the most common data collection approach for both phenomenological and grounded theory studies (Creswell, 2013), an online structured questionnaire was administered to the participants instead. This enabled the participants to respond to the items at a place and time that was convenient for them. The questionnaire consisted of three parts: a set of items related to participants' flight experience, a set of constructed response items related to their VFR-into-IMC experience, and a set of items related to their personal demographics. Prior to implementing the study, the host university's Institutional Review Board reviewed and approved the study and its corresponding protocols.

Each member of the research team targeted a GA pilot whom he or she knew experienced an inadvertent VFR-into-IMC flight, and who would provide rich data. The targeted participants were contacted via a personal e-mail message with information about the study that included a request to participate with a link to the online questionnaire. Each participant who was contacted agreed to participate. Thus, there was no need to pursue any additional solicitations. The data from the questionnaires were collected between March and April 2014, and then again between March and April 2015. Based on the summary statistics provided by the online hosting site, participants averaged between 20 and 25 minutes to complete the 30 -item questionnaire.

\section{Standards of Rigor in Qualitative Research}

The concept of rigor in qualitative research refers to questions of validity and reliability, which involves making valid inferences from the data and determining the extent to which the data are consistent. Creswell (2013, pp. 244-250) presented many different perspectives about how qualitative researchers could address the concept of rigor in their studies. Of the various perspectives, though, the single most commonly cited one is from Lincoln and Guba (1985), which focused on (quantitative analogs in parentheses): credibility (internal validity), transferability (external validity), dependability (reliability), and confirmability (objectivity).

Credibility was addressed in the current study through structural corroboration, consensus, and interpretive adequacy (Ary, Jacobs, \& Sorensen, 2010, p. 498). Structural corroboration was provided in the form of methods triangulation by employing two independent qualitative approaches: phenomenology and grounded theory. The first approach was used to acquire participants' first-hand experiences; the second approach was used to develop inductively a conjecture-based framework, which could be used subsequently for theory building. Consensus was achieved via peer debriefing in which the major author initially assumed the role of "devil's advocate" to challenge the other research team members about the reasonableness of their interpretations and explanations. The research team members also assumed this role as they challenged each other's interpretations of the data. Interpretive adequacy was provided using low-inference descriptors, which included direct quotations to accurately portray participants' views, 
thoughts, feelings, and experiences. One limitation to credibility, though, was the lack of data triangulation. The study used a single data source, the online questionnaire, which was administered as a one-time event with no follow-up via member checking or with no additional data sources such as face-to-face interviews or e-mail correspondences.

Transferability was addressed through descriptive adequacy and similarity (Ary et al., 2010 , p. 502). With respect to the former, accurate, detailed, and complete descriptions of the context and participants were developed; with respect to the latter, the findings of the current study were compared to the current literature, and limitations were identified. Attention to dependability was given via interrater/interobserver agreement relative to the common themes and patterns that emerged from participants' responses. Attention to confirmability was through peer review and methods of triangulation, both of which were discussed in the foregoing paragraph.

\section{Results}

Data analysis was conducted in two stages. During the first stage, participants' written responses were carefully reviewed to see if they were commensurate with the research questions. During the second stage, a search for similar comments, common patterns, and themes was conducted. The qualitative software, Nvivo, was used for the 2104 data to assist in this search, but because of the larger class size in 2015 (eight students vs. three students in 2014), the 2015 data were analyzed without the aid of any computer software. As the analysis progressed, labels such as preflight, en route, recognition, and lessons learned were assigned to represent the common themes and patterns that emerged. These labels, which were discussed collectively as a group and relative to each research question, underwent several changes until everyone agreed on the final list.

To help categorize the common themes and patterns, Spradley's (1979) domain analysis was applied. Three major domains emerged from the data: Weather Considerations and Expectations, Thoughts and Actions, and Postflight Experiences. These domains were further partitioned into subcategories that Spradley referred to as cover terms and included terms. Several cover terms relative to each domain were identified, but every cover term was not further partitioned into an included term unless the data warranted additional refinement. Tables 2, 3, and 4 contain a summary of this process for each respective domain. Each sequence of "domain-cover term" or "domain-cover term-included term" then led to corresponding conjectures. As an example, consider the sequence associated with Conjecture 2.2 in Table 3 for Domain 2, "Thoughts and Actions." This sequence and corresponding conjecture is read as "GA pilots' thoughts and actions during IMC flight covered recognition of their situation and included their use of various communication resources to assess their current situation"; therefore, "With respect to thoughts and actions during IMC flight: GA pilots who inadvertently fly VFR-into-IMC will use various communication resources to assess their current situation." This data analysis process reflects a grounded theory approach (Glasser \& Strauss, 1967) in which theory-or in the context of the current study, conjectures- "is inductively derived from the study of the phenomenon it represents" (Strauss \& Corbin, 1990, p. 23). A discussion of the findings relative to each domain follows. 
Table 2

GA Pilots' Considerations and Expectations with Respect to Weather

\begin{tabular}{|c|c|c|c|}
\hline Domain 1 & $\begin{array}{l}\text { Cover } \\
\text { Term }\end{array}$ & $\begin{array}{c}\text { Included } \\
\text { Term }\end{array}$ & $\begin{array}{l}\text { Conjectures } \\
\text { With respect to weather considerations and expectations: } \\
\text { GA pilots who inadvertently fly VFR-into-IMC will ... }\end{array}$ \\
\hline \multirow{4}{*}{$\begin{array}{l}\text { Weather } \\
\text { Considerations } \\
\text { and } \\
\text { Expectations }\end{array}$} & Preflight & - & $\begin{array}{l}\text { 1.1. consult a weather briefer (human or computer) as part of } \\
\text { their preflight actions prior to departure and make their } \\
\text { own interpretations of the information they acquire. }\end{array}$ \\
\hline & & & $\begin{array}{l}\text { 1.2. focus on cloud ceilings and visibility and give little } \\
\text { consideration to overall weather conditions or of } \\
\text { encountering poor weather conditions. }\end{array}$ \\
\hline & & & 1.3. neither expect nor anticipate IMC. \\
\hline & En Route & - & $\begin{array}{l}1.4 \text { use a variety of communications sources such as radio, } \\
\text { ATIS, and cell phone to keep current with weather- } \\
\text { related issues. }\end{array}$ \\
\hline
\end{tabular}

\section{Domain 1: Weather Considerations and Expectations}

Domain 1 corresponded to the first research question: In what way do pilots use weather related information throughout their VFR-into-IMC flight? In responding to the questionnaire items related to this question, participants interpreted the phrase "throughout their VFR-into-IMC flight" to mean how they used weather information during both preflight and en route. As a result, their responses led to two separate cover terms: preflight and en route. Table 2 contains a summary of the major themes and corresponding conjectures associated with Domain 1.

Preflight. Based on their comments, it appeared that the pilots of the current study followed standard preflight protocols with the majority of the participants indicating they received a weather briefing as part of their preflight actions prior to departure. For example: P8 said, "Check the weather as usual and get a standard weather brief"; P9 reported "I checked all the weather sources including FSS"; and P10 said, "Got wx brief, forecasts, NOTAMs, etc. (related to) that flight." So based on these responses, it appears that the participants acquired weather information prior to departure on their own from either human or computer sources and then made their own interpretations.

Although not prevalent throughout, various comments seemed to suggest that some pilots did not consistently give serious consideration to the weather. For example, P1 reported, "I was not anticipating going into IMC..." P1 further qualified this statement as follows:

We have 2500 to 3000 feet of ceiling (so) there's no need for more consideration of weather so we did not have a lot of weather briefing honestly...just checking the ceiling because it was a local flight...This is the usual habit: just checking the ceiling and surrounding airports and just go fly. 
P3's experience accented this preflight weather mindset by indicating that prior to take-off, "I print(ed) all METAR and TAF en route weather (and) ... there was no problem for me." However, after take-off P3 reported "I didn't listen to ATIS again from Melbourne airport. Unfortunately, when I was traveling, I was flying from Vero Beach to Melbourne they had issued a special observation and that observation was IMC conditions." Thus, in P3's case, he planned for weather preflight, but was not diligent in following through with a full weather briefing from flight service station.

These comments about what participants' did with respect to preflight weather considerations and expectations led to the following conjecture: GA pilots who experience an inadvertent VFR-into-IMC flight will (a) consult a weather briefer (human or computer) as part of their preflight actions prior to departure and make their own interpretations of the information they acquire, (b) focus on cloud ceilings and visibility and give little consideration to overall weather conditions or of encountering poor weather conditions, and (c) neither expect nor anticipate IMC.

En route. During the en route stage of their flight, participants reported they relied on a variety of communication sources to keep current with weather-related issues. These sources included radio communication, ATIS, and cell phone. For example: P9 reported, "taking ATIS information," and P10 relied on his cell phone for text messages from his instructor and his radio to receive "ATIS, approach and dispatch frequencies." In addition to these communication sources, $\mathrm{P} 8$ relied on visual inspection and radio monitoring: "Watch(ed) outside and listened (to) other pilots (on) the radio."

These comments about what participants did with respect to weather considerations and expectations en route led to the following conjecture: GA pilots who experience an inadvertent VFR-into-IMC flight will use a variety of communications sources such as radio, ATIS, and cell phone to keep current with weather-related issues.

\section{Domain 2: Thoughts and Actions}

Domain 2 corresponded to the second research question: "What are pilots' thoughts and actions when they realize they are in IMC? Participants' responses to the questionnaire items that were relevant to this second research question led to three major themes: recognition that the weather was deteriorating, reaction to the situation, and their thoughts about their situation either just prior to or during the time they were in IMC. Table 3 contains a summary of the major themes and corresponding conjectures associated with Domain 2.

These comments led to the following conjecture: GA pilots who experience an inadvertent VFR-into-IMC flight will (a) recognize changes in the weather and (b) use various communication resources to assess their current situation.

Reaction. In addition to recognizing the deteriorating weather, and independent of the communication resources they used to assess their situation, several participants also 
reported what they did either in anticipation of encountering IMC or during IMC. The most prevalent theme was related to the notion of "avoid and escape." As an illustration, consider the respective comments from $\mathrm{P} 7, \mathrm{P} 10$, and P11:

P7: I saw high clouds in front of me but like a wall and low base so I started to climb. At a point since they were moving towards me I couldn't climb steeper and instead of stalling I went into the clouds. Immediately turned 180 and descended and I got out of it.

P10: There were scattered clouds that developed into an overcast layer. The sky was scattered when I took off but cloud formation was on progress and ceiling was lowering. It turned to overcast in $1.5 \mathrm{hrs}$ although TAF was saying it would become OVC in 4 hours. I flew to my first destination but couldn't come back to my base so I had to divert to another airport on my way. I did everything what I was taught and told accordingly so I managed to divert safely.

P11: I searched for a hole in the clouds and tried to remain in the same position because I did not have any radio navigation equipment. I used the knowledge of my present position over the sea and turned to a heading that would keep me over the sea during the descent.

Table 3

GA Pilots' Thoughts and Actions during IMC Flight

\begin{tabular}{|c|c|c|c|}
\hline Domain 2 & $\begin{array}{l}\text { Cover } \\
\text { Term }\end{array}$ & $\begin{array}{l}\text { Included } \\
\text { Term }\end{array}$ & $\begin{array}{l}\text { Conjectures } \\
\text { With respect to thoughts and actions during IMC flight: } \\
\text { GA pilots who inadvertently fly VFR-into-IMC will ... }\end{array}$ \\
\hline \multirow{6}{*}{$\begin{array}{l}\text { Thoughts } \\
\text { and Actions }\end{array}$} & \multirow[t]{2}{*}{ Recognition } & Observation & recognize changes in the weather. \\
\hline & & $\begin{array}{l}\text { Use of } \\
\text { Resources }\end{array}$ & $\begin{array}{l}\text { use various communication resources to assess their current } \\
\text { situation. }\end{array}$ \\
\hline & Reaction & $\begin{array}{l}\text { Avoid and } \\
\text { Escape }\end{array}$ & $\begin{array}{l}\text { react to change in the weather by using their instruments, } \\
\text { climbing steeper, descending, turning } 180 \text { degrees, and } \\
\text { diverting to another airport to get out of IMC. }\end{array}$ \\
\hline & \multirow[t]{3}{*}{ Thoughts } & Emotion & $\begin{array}{l}\text { have feelings of trepidation about what they should do that } \\
\text { span the spectrum of possible scenarios, including whether } \\
\text { to continue or divert, or maintain or change altitude. }\end{array}$ \\
\hline & & & $\begin{array}{l}\text { express surprise over how the weather they encountered was } \\
\text { not what they expected based on the weather information } \\
\text { they received and interpreted prior to departure. }\end{array}$ \\
\hline & & $\begin{array}{l}\text { Recollection } \\
\text { of training }\end{array}$ & $\begin{array}{l}\text { revert to their training and fly the aircraft, and trust their } \\
\text { instruments. }\end{array}$ \\
\hline
\end{tabular}


Participants also reported that they focused on their instruments as part of their "avoid and escape" reaction. For example, P7 said he "trusted to the instruments" and used "the attitude indicator and altimeter," and P11 said, "I tried to keep a straight descending flight by monitoring the flight instruments (specifically the airspeed indicator, the heading indicator, altimeter, and the inclinometer)."

These comments about participants' reactions led to the following conjecture: GA pilots who inadvertently experience VFR-into-IMC during the en route stage of their flight will react to changes in the weather by doing whatever they could to get out of IMC, including using their instruments, climbing steeper, descending, turning 180 degrees, and diverting to another airport.

Thoughts. In addition to their recognition of and reaction to the changes in the weather, participants also shared with us what they were thinking when they realized they were going to encounter IMC. Their thought processes included their emotions as well as recollection of their training. With respect to their emotions, participants' first thoughts appeared to be mental anguish, or trepidation, over what they should do. For example, P6 said:

I wanted to get home. I knew immediately that once I (flew) into (IMC), but I was hoping to fly out of them so I continued. I was stressed, I was nervous. I knew I was in a situation that was hazardous.

This feeling of trepidation also was echoed by P1 who reported:

During the beginning of the event, it was a little bit intense because the fear of traffic plus I was flying an airplane that did not have an ADS-B (automatic dependent surveillance broadcast). So I was literally flying blind for the couple of minutes I spent without IFR clearance.

Other participants also expressed a similar emotion as captured by the following remarks:

P7: (I thought about) turning back to where I came.

P8: Should I continue?

P9: I thought I was in danger (and) I tried to stay calm and started to think about the probability of being in that cumulonimbus cloud.

P10: (I should) descend to an altitude at which I could see visual references and divert to the nearest suitable airport where I can land in VMC conditions.

The participants also expressed an emotion of surprise that the weather had changed. For example, P10 indicated he was expecting poor weather prior to take-off but "the bad wx I was expecting before the flight came 2.5 hours earlier." This earlier than expected bad 
weather also was reported by P9 who said "It occurred in an hour unexpectedly." Because the participants, as reported in Research Question 1, interpreted their own weather information prior to departure, it appeared that perhaps P9 and P10 did not accurately interpret the data they received given their surprise over how quickly the weather deteriorated en route.

These comments about participants' thoughts led to the following conjecture: GA pilots who experience an inadvertent VFR-into-IMC flight during the en route stage of their flight will (a) have feelings of trepidation about what they should do that span the spectrum of possible scenarios, including whether to continue or divert, or maintain or change altitude; and (b) express surprise over how the weather they encountered was not what they expected based on the weather information they received and interpreted prior to departure.

In addition to their emotions, some participants also seemed to be thinking about their training. For example, P2 said:

The key to my training is to aviate then navigate then communicate. You have to fly; you don't get distracted. You stay on the gauges; you continue to fly. No matter if you're banging around or losing heading, you still have to focus on your aviation: Fly the aircraft first.

P2 accented his remark by stating, "Steady reliance and trust in your instruments. You have to trust your instruments and so I did that and managed to continue the flight." P1 continued this theme by reporting on the importance of training. "The first (thought) is directly from 'the book,' always trust your instruments and fly according to them." P3's thought was with respect to the "book knowledge" he was receiving via ground training regarding instrument flying:

The training told me if I enter, I can't enter the clouds (and) I should divert to another VFR airport. But the second part of it, at the same time, I was (taking) my instrument training ground school and the ground school told me if you are in the clouds just rely on your instruments, and I did. Honestly, when I was in the clouds, I didn't look outside so I didn't have any spatial disorientation because of the clouds...I was just looking (at) my instruments.

Lastly, P5 said, "I recognized the situation and (my thought was to) follow my training and immediately (went) into instruments and stabilized the aircraft."

These comments about participants' recollection of their training led to the following conjecture: GA pilots who experience an inadvertent VFR-into-IMC flight during the en route stage of their flight will revert to their training and fly the aircraft, and trust their instruments. 
Table 4

GA Pilots' Retrospective Thoughts on VFR-into-IMC Flight

\begin{tabular}{|c|c|c|c|}
\hline Domain 3 & Cover Term & $\begin{array}{c}\text { Included } \\
\text { Term }\end{array}$ & $\begin{array}{c}\text { Conjectures } \\
\text { With respect to pilots' retrospective thoughts: } \\
\text { GA Pilots who inadvertently fly VFR-into-IMC will... }\end{array}$ \\
\hline \multirow[t]{3}{*}{$\begin{array}{l}\text { Postflight } \\
\text { Experiences }\end{array}$} & $\begin{array}{l}\text { Postflight } \\
\text { Actions }\end{array}$ & - & $\begin{array}{l}\text { 3.1. have postflight actions that range from doing nothing } \\
\text { to filing a report to NASA's Aviation Safety } \\
\text { Reporting System (ASRS). }\end{array}$ \\
\hline & $\begin{array}{l}\text { Lessons } \\
\text { Learned } \\
\text { Overall }\end{array}$ & - & $\begin{array}{l}\text { 3.2. have a heightened sense of situational awareness. } \\
\text { 3.3. recognize they need to do a better job in alternative } \\
\text { planning. }\end{array}$ \\
\hline & $\begin{array}{l}\text { Lessons } \\
\text { Learned about } \\
\text { the Weather }\end{array}$ & - & 3.4. have a heightened appreciation for the weather. \\
\hline
\end{tabular}

\section{Domain 3: Postflight Experiences}

Domain 3 corresponded to the third research question: "What are pilots' retrospective thoughts on their VFR-into-IMC flight experiences?" Participants' responses to the questionnaire items that were relevant to this third research question led to three major themes: postflight actions, lessons learned overall, and lessons learned about the weather. Table 4 contains a summary of the major themes and corresponding conjectures associated with Domain 3.

Postflight actions. Participants' postflight actions ranged from doing nothing to filing a report with NASA's ASRS. For example, P8 reported doing "nothing" and P9 said, "There wasn't any need for doing anything." On the other hand, P10 reported that he "Informed every related person about the situation and spent the night in a hotel in another city," and P11 said, "I told my instructor, but I did not report the incident." Of all of the participants, only P7 said he "filed a NASA report."

These comments about participants' postflight actions led to the following conjecture: GA pilots who experience an inadvertent VFR-into-IMC flight during the en route stage of their flight will range from doing nothing to filing a report to NASA's ASRS.

Lessons learned overall. The participants reported learning several lessons from their experiences. These ranged from engaging in alternative planning to situational awareness to informing the tower of their actions to diverting. For example:

P2: I believe I would have diverted.

P3: Absolutely! I would redirect to Okeechobee because I knew Okeechobee (had) VFR conditions that day. 
P6: I would have turned around and landed in Gainesville or some other airport that was VFR. I would have gotten an updated weather briefing and proceeded much more cautiously. I would have waited for the weather to move until I had VFR conditions to my destination.

P7: (I learned) how and when to take action in case of similar situation.

P8: I would return to base or divert to a suitable airport.

P9: (I learned that) alternate planning must be made carefully (and I would do a) much better (job at) alternate planning.

P10: Stay awake, be aware and evaluate the situation by asking yourself "what is next?"

P11: I would have done the same actions, but I would have contacted the tower and told them what I planned to do.

Unlike the 2015 sample, the 2014 participants also reported they considered their VFRinto-IMC experience as a worthwhile training event that they never could have received from formal training. For example, P3 said, "After this flight, I think my risk demand is a little bit weakened compared to the past. I mean, this is not the stock exchange anymore; this is life." P4 also described how his VFR-into-IMC flight changed his perspective of flight training:

I attribute the change to having the realization that flying is actually dangerous. Before I was young and dumb and felt invincible, and that the system was so safe in the U.S. and that nothing bad could happen. After that (this experience) I kind of had a reality check. I am a far safer pilot now.

Finally, P1 commented, "Definitely. I learned to have the bigger picture; even for small flights in the area."

These comments about what participants' learned overall from their VFR-into-IMC experience led to the following conjecture: GA pilots who experience an inadvertent VFRinto-IMC flight will have a heightened sense of situational awareness and recognize they need to do a better job in alternative planning.

Lessons learned about weather. Independent of lessons learned overall, participants also reported learning several lessons about weather. For example, P7 reported he needs to "Read the weather chart better" and that "After this situation I choose to fly over (the) coast mostly since there are less clouds." P1 said, "The only thing that changed is my weather briefing. For local flights, I do not only look for METARs and TAFs, I check everything now to prevent going into IMC." Other comments relative to lessons learned about the weather included: 
P8: Do not risk the weather (if it) is marginal.

P10: Never trust wx forecasts totally, get as much information as you can get, always observe the environment about the changes.

P11: Check the weather forecast before flight, and be sure to assess the weather continuously during flight.

These comments about what participants' learned about the weather from their VFRinto-IMC experience led to the following conjecture: GA pilots who experience an inadvertent VFR-into-IMC flight will have a heightened appreciation for the weather.

\section{Summary and Discussion}

With respect to Domain 1, Weather Considerations and Expectations (Table 2), although all participants received a weather briefing as part of their preflight actions, they still encountered VFR-into-IMC during the en route phase of their flight. This finding is consistent with those of Knecht and Lenz (2010), Ison (2014), and Shappell et al. (2010). As noted earlier, Knecht and Lenz reported that of the 100 VFR-into-IMC ASRS incident reports they analyzed, pilots in 95 of them indicated they received preflight weather briefings. Ison (2014) also reported that pilots who were involved in a fatal accident that was classified as VFR-into-IMC were "19 times more likely to have received a weather briefing" (p. 17). Shappell et al. reported, "All pilots had obtained some type of weather information prior to departure on the day of the weather encounter, and most (76.0\%) accessed weather information less than 30 minutes before departure" (p. 6). The participants in the current study also indicated that based on their preflight weather briefing they neither expected nor anticipated IMC en route. This finding provides support to Goh and Wiegmann's (2001) speculation that "...erroneous assessment of weather conditions may cause...some pilots to fly into IMC unwittingly" (p. 5) as well as Ison who surmised that pilots do not seem to be grasping the required knowledge to evaluate weather reports (p. 22).

When the findings associated with Domain 1 are considered collectively, it appears that the participants of the current study relied on their own interpretation of the weather briefing information they received and did not give sufficient attention to the possibility that they might encounter deteriorating weather conditions. This also suggests that the participants might be relying too heavily on forecasts and/or they do not truly understand the difference between a forecast and reality. One plausible reason for this is that many flight schools train pilots to base their go/no-go preflight decision on cloud ceilings and visibility, which could lead pilots to overemphasize these areas in their preflight weather forecasting. The findings related to Domain 1 also could be due to the participants' relative inexperience, particularly with the 2015 sample, which had a mean age of 31.4 years old and a mean of 411 flight hours (Table 1). In light of the FAA's (2013a) 1500-hour rule, which increased the minimum number of hours required to be a first officer from 250 hours to 1500 hours, it is possible that the participants did not have enough weather experience. 
Although what might appear to be a blasé preflight attitude about the weather, this seemed to be mitigated somewhat en route because the participants indicated they kept current with the weather. Nevertheless, given that the trend for preflight weather briefing is toward pilot self-briefing (Casner, Murphy, Neville, \& Neville, 2012; FAA, 2013b), the findings related to Conjectures 1.1 and 1.3 of the current study raise a red flag about GA pilots' ability to correctly interpret weather information.

With respect to Domain 2, Thoughts and Actions (Table 3), because participants kept current with the weather en route, they were able to recognize changes in the weather, assess their current situation relative to the weather, and take action to either avoid or escape IMC. As noted in Conjecture 2.3 (Table 3), the actions participants took involved climbing steeper, descending, turning 180 degrees, and diverting to another airport to get out of IMC. These findings are consistent with those of Knecht and Lenz (2010) and Shappell et al. (2010). Knecht and Lenz reported that the three most frequently used recovery strategies cited by non-IR pilots were descend to stay below the weather, perform a 180-degree turn, and land at an alternative site. Shappell et al. reported

...the majority of pilots $(92.0 \%)$ deviated at some point from their planned route or altitude...(and)...the majority who deviated (73.9\%) did so after encountering the weather. Even though a majority of the participants deviated, $87.5 \%$ were aware of where they were relative to their course and location. (pp. 7-8)

Concomitant with participants' actions were various emotions they experienced, including feelings of apprehensiveness and worry about what specific actions they should take, and feelings of surprise over how the weather was not what they expected preflight. This finding seems to support Csikszentmihalyi's $(1990,2014)$ flow theory, which posits a relationship between a person's perceived skill level and his/her perceived understanding of the challenge level of a task. As an example, consider a GA pilot who perceives a particular challenge as being relatively low such as a cross-country trip on a clear day the pilot has made several times before. As the pilot's skill level varies from low to moderate to high, his or her mental state would also change commensurately from apathy to boredom to relaxation. However, as the challenge level increases (e.g., encountering IMC en route unexpectedly), and the perceived skill level is low-to-moderate, then the pilot will experience states of worry and anxiety. This appears to be exactly what the participants reported. They perceived their flight as not being challenging, and they were neither expecting nor anticipating deteriorating weather conditions en route. Once they encountered IMC, though, they entered a state of worry.

Ultimately the participants gathered their thoughts and relied on their training experiences to help resolve their situation. This latter finding underscores the importance of training, particularly instrument training. This finding also gives credibility to the current emphasis in VFR training, which is to require basic instrument flying. This finding also provides support for a new, separate rating called the En route Instrument Rating (EIR), which is now available in the United Kingdom and permits holders of an EIR to conduct flights by day under IFR during the en route phase of flight (Civil Aviation 
Authority, 2014, p. 1). Holders of an EIR, however, are prohibited from accepting "an IFR clearance to fly a departure, arrival or approach procedure" (p. 2).

With respect to Domain 3, Postflight Experiences (Table 4), the only postflight action that emerged was whether or not the participants reported their VFR-into-IMC experience. Some opted to not report what happened whereas others did so. This suggests that some GA pilots might be apprehensive in documenting any irregularities they experienced en route. Nevertheless, the participants indicated that their VFR-into-IMC experience made them more sensitive to maintaining situational awareness, and it alerted them to the need for alternative planning. Taken separately, the former provides partial support to Wiegmann et al.'s (2002) situation assessment explanation theory; the latter strengthens Knecht and Lenz's (2010) position that non-IR and unseasoned IR pilots need to consider and develop alternative actions about what to do in the event they encounter adverse weather before they are needed and not wait until the last minute (p. 22).

One manifestation of the participants' surviving an inadvertent VFR-into-IMC flight was a much greater appreciation and respect for the weather. What is most pronounced is the juxtaposition of Conjectures 1.1, 1.3, and 3.4. When viewed as a single entity, this juxtaposition implies that GA pilots have an incorrect perception of their weather knowledge. The participants clearly articulated that although they did their due diligence with respect to acquiring a preflight weather briefing, they were surprised by the change in weather, neither expected nor anticipated IMC, and now have a greater appreciation for the weather as a result of their VFR-into-IMC experience. This revelation supports the findings reported by Burian (2002) who administered a weather knowledge test to 1005 GA pilots with a PPL rating and PIC certificate for at least visual meteorological conditions (VMC). Burian found that the participants performed poorly on the test and concluded that "Many pilots apparently lack operationally relevant weather knowledge and/or have difficulty recalling what was once learned" and that "VFR-only pilots performed significantly worse than" IR pilots, CFIs, and ATPs (p. iv). The implication from juxtaposing Conjectures 1.1, 1.3, and 3.4 also is consistent with some of Wiegmann, Talleur, and Johnson's (2008) explanations of why pilots fly into adverse weather: lack of knowledge and experience, limited weather evaluation skills, and poor in-flight planning. This implication also supports Shappell et al.'s (2010) concluding comment: "Contrary to what the accident record seems to suggest, flight into adverse weather seems to be primarily due to the lack of appreciation/understanding of the hazards associated with adverse weather" (p. 12).

\section{Limitations and Recommendations}

\section{Limitations}

Given the nature of the current study, several limitations are warranted. First, it should be noted that we had no control over participants' flight experiences or personological characteristics as reported in Table 1. Second, we chose to focus on inadvertent VFR-intoIMC flights. Third, data collection was restricted to a one-time event and was conducted via an online survey-hosting site with no face-to-face interviews, follow-up, or member

checking. Fourth, the questionnaire items were prepared collectively by the research team 
and served as the only data source. Fifth, the majority of participants' inadvertent VFRinto-IMC flights occurred in Florida, which many within the aviation community regard as "airport-friendly" because there are many airports located within close proximity of each other.

\section{Recommendations}

The findings of the current study led to a set of recommendations for practice as well as to a set of recommendations for future research. With respect to practice, we recommend:

1. The flight instruction curriculum should increase its coverage of weather and consider adding more emphasis to weather training.

2. The flight instruction curriculum should include VFR-into-IMC simulation training.

3. The flight instruction curriculum should continue training on how to escape inadvertent VFR-into-IMC situations.

4. GA pilots should be encouraged to document their experience of any irregularities en route, including encountering inadvertent IMC during a VFR flight, so others can learn from their experiences.

5. The FAA should consider applying the United Kingdom's En route Instrument Rating (EIR) to the GA flight training curriculum.

With respect to future research, we recommend:

1. Future studies should include data triangulation by incorporating face-to-face interviews and e-mail correspondence as supplemental data sources to increase the credibility of the study.

2. Future studies should include female pilots.

3. Future studies should include pilots who experienced inadvertent VFR-into-IMC flights outside the state of Florida.

4. Future studies might consider including a mixed methods approach by measuring pilots' hazardous attitudes and then mapping them to pilots' responses to the questionnaire items and interview responses.

5. Future studies should investigate the deficiencies in weather training for GA pilots.

Lastly, we encourage replication studies be conducted to validate the findings of the current study as well as confirm the conjectures that emerged as outlined in Tables 2, 3, and 4. We also encourage researchers who analyze VFR-into-IMC incident/accident reports from 
NTSB, FAA, or ASRS databases to determine if their findings support or refute these conjectures, or if they require further modifications. 


\section{References}

Aircraft Owners and Pilots Association (2002). AOPA air safety foundation. Accident trends and factors for 2001: The Nall report. Retrieved from http://www.aopa.org//media/Files/AOPA/Home/News/All-News/2003/Answers-for-Pilots-(9)/02nall.pdf

Aircraft Owners and Pilots Association (2015). VFR into IMC accidents. Retrieved from http://www.aopa.org/asf/ntsb/vfrintoimc.cfm?window=1

Arkes, H. R., \& Blummer, C. (1985). The psychology of sunk costs. Organizational Behavior and Human Decision Processes, 35, 124-140.

Ary, D., Jacobs, L. C., \& Sorensen, C. (2010). Introduction to research in education (8th ed.). Belmont, CA; Wadsworth, Cengage Learning.

Aviation Safety Reporting System (2015). Immunity policies: Advisory circular 00-46E. Retrieved from http://asrs.arc.nasa.gov/overview/immunity.html

Aviation Safety Study (1990, November 13). Report of a safety study on VFR flight into adverse weather. Report Number 90-SP002. Retrieved from http://www.bsttsb.gc.ca/eng/rapports-reports/aviation/etudes-studies/90sp002/90sp002.asp

Batt, R., \& O'Hare, D. (2005). General aviation pilot behaviours in the face of adverse weather. Aviation Research Investigation Report B2005/0127. Retrieved from https://www.atsb.gov.au/media/36438/Pilot_behaviours_adv.pdf

Bazargan, M. (2005). Statistical analysis for general aviation accidents: Analysis of national top 10 first causes of fatal accidents of general aviation between 1983 and 2002. Daytona Beach, FL: Embry-Riddle Aeronautical University, Aviation Operation Simulation Lab.

Burian, B. K., (2002). General Aviation Pilot Weather Knowledge and Training, final report of the FAA, grant \#00-G-020. Retrieved from https://www.hf.faa.gov/hfportalnew/Search/DOCs/NASAWxCFI.pdf

Casner S. M., Murphy, M. P., Neville, E. C., and Neville, M. R. (2012). Pilots as weather briefers: The direct use of aviation weather products by general aviation pilots. The International Journal of Aviation Psychology, 22(4), 367-381. DOI $10.1080 / 10508414.2012 .718241$

Civil Aviation Authority (2014, October 10). Introduction of the part-FCL en-route instrument rating in the United Kingdom. Information notice: Number IN-2014/169. Retrieved from http://www.caa.co.uk/docs/33/InformationNotice2014169.pdf

Creswell, J. W. (2013). Qualitative inquiry and research design: Choosing among five approaches (3rd. ed.). Los Angeles, CA: SAGE Publications. 
Csikszentmihalyi, M. (1990). FLOW: The psychology of optimal experience (pp. 71-93). New York, NY: Harper and Row.

Csikszentmihalyi, M. (2014). Flow and the foundations of positive psychology: The collected works of Mihaly Csikszentmihalyi. New York, NY: Springer Dordrecht Heidelberg.

Federal Aviation Administration. (2013a). Press Release_FAA Boosts Aviation Safety with New Pilot Qualification Standards. Retrieved from https://www.faa.gov/news/press_releases/news_story.cfm?newsId=14838

Federal Aviation Administration. (2013b). 2011-2012 Flight service metrics version 1.0. Retrieved from https://faaco.faa.gov/index.cfm/attachment/download/32187

Federal Aviation Administration. (2014). Pilot/controller glossary. Retrieved from http://www.faa.gov/documentlibrary/media/order/pcg_errata.pdf

Glasser, B., \& Strauss, A. (1967). The discovery of grounded theory. Chicago, IL: Aldine.

Goh, J., \& Wiegmann, D. A. (2001). Visual flight rules (VFR) into instrument meteorological conditions (IMC): A review of the accident data. Paper presented at the 11th International Symposium on Aviation Psychology, Columbus, OH. Retrieved from http://www.researchgate.net/publication/252217964

Goh, J., Wiegmann, D., \& O'Hare, D. (2002). The effects of distance traveled and pilot experience on pilot's decisions to continue visual flight rules flight into adverse weather. Aviation, Space, and Environmental Medicine, 73(3), 252-253.

Ison, D. (2014). Correlates of continued visual flight rules (VFR) into instrument meteorological conditions (IMC) general aviation accidents. Journal of Aviation/Aerospace Education \& Research, 24(1). Retrieved from http://commons.erau.edu/cgi/viewcontent.cgi?article=1628\&context=jaaer

Knecht, W. (2008a). Use of weather information by general aviation pilots, part I, quantitative: Reported use and value of providers and products. Final Report DOT/FAA/AM-08/6. Retrieved from http://www.dtic.mil/cgibin/GetTRDoc?AD=ADA481118

Knecht, W. (2008b). Use of weather information by general aviation pilots, part II, qualitative: Exploring factors involved in weather-related decisions. Final Report DOT/FAA/AM-08/7. Retrieved from http://www.faa.gov/data_research/research/med_humanfacs/oamtechreports/2000s/m edia/200807.pdf 
Knecht, W. R., \& Lenz, M. (2010). Causes of general aviation weather-related, non-fatal incidents: Analysis using NASA aviation safety reporting system data. Final Report DOT/FAA/AM-10/13. Retrieved from http://www.faa.gov/data_research/research/med_humanfacs/oamtechreports/2010s/m edia/201013.pdf

Levy, J. S. (1992). An introduction to prospect theory. Political Psychology, 13(2), 171186.

Lincoln, Y., \& Guba, E. (1985). Naturalistic inquiry. Thousand Oaks, CA: Sage.

National Aeronautics and Space Administration (2007). General aviation weather encounters 2007. NASA ASRS, Publication 63. Retrieved from http://asrs.arc.nasa.gov/docs/rs/63_ASRS_GA_WeatherEncounters.pdf

National Transportation Safety Board. (1989). Safety report: General aviation accidents involving visual flight rules flight into instrument meteorological conditions. Report NTSB-SR-89-01. Retrieved from http://libraryonline.erau.edu/online-fulltext/ntsb/safety-reports/SR89-01.pdf

National Transportation Safety Board. (2005). Risk factors associated with weatherrelated general aviation accidents. Report NTSB/SS-05/01. Retrieved from http://www.ntsb.gov/safety/safety-studies/Documents/SS0501.pdf

National Transportation Safety Board. (2013). Aviation accident statistics. Retrieved from http://www.ntsb.gov/_layouts/ntsb.aviation/index.aspx

O’Hare, D., \& Smitheram, T. (1995). "Pressing on" into deteriorating conditions: An application of behavioral decision theory to pilot decision making. The International Journal of Aviation Psychology, 5(4), 351-370.

Shappell, S., Hackworth, C., Holcomb, K., Lanicci, J., Bazargan, M., Baron, J., Iden, R., \& Halperin, D. (2010). Developing proactive methods for general aviation data collection. Final Report DOT/FAA/AM-10/16. Retrieved from http://www.faa.gov/data_research/research/med_humanfacs/oamtechreports/2010s/m edia/201016.pdf

Spradley, J. P. (1979). The ethnographic review. New York, NY: Holt, Rinehart, and Winston.

Strauss, A., \& Corbin, J. (1990). Basics of qualitative research: Grounded theory and procedures and techniques. Los Angeles, CA: SAGE Publications.

VFR into IMC Accidents 02/07/2014 - 02/07/2015 (2015, May 7). Retrieved from http://www.aopa.org/asf/ntsb/vfrintoimc.cfm?window=1 
Wiegmann, D. A., Goh, J., \& O'Hare, D. (2002). The role of situation assessment and flight experience in pilots' decisions to continue visual flight rules flight into adverse weather. Human Factors: The Journal of the Human Factors and Ergonomics Society, 44(2), 189-197.

Wiegmann, D., Talleur, D., \& Johnson, C. (2008). Evaluating weather-related training and testing of general aviation pilots. Proceedings of the 2nd Annual Meeting of the Human Factors and Ergonomics Society, New York, NY.

Wiggins, M. (1993). Aeronautical experience and weather-related decision making amongst pilots: A cross-sectional analysis. Unpublished master's thesis, University of Otago, Dunedin, New Zealand.

Wilson, D. R., \& Sloan, T. A. (2003). VFR flight into IMC: Reducing the hazard. Journal of Aviation/Aerospace Education \& Research, 13(1), 29-42. 